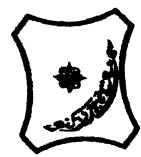

Bayero Journal of Pure and Applied Sciences, 10(2): 69 - 74

Received: October, 2017

Accepted: December, 2017

ISSN $2006-6996$

\title{
SEXUAL DIMORPHISM IN VISCERAL ADIPOSITY MEASURES, PARAMETERS AND BIOMARKERS OF METABOLIC SYNDROME AMONG HAUSA ETHNIC GROUP IN KANO, NIGERIA
}

\author{
*Asuku, A.Y., ${ }^{1}$ Danborno, B., ${ }^{2}$ Akuyam, A.S., ${ }^{3}$ Timbuak, J. A2 . and Adamu, L.H. ${ }^{1}$ \\ ${ }^{1}$ Department of Anatomy, Faculty of Basic Medical Sciences, College of Health Sciences, Bayero University, Kano, \\ P.M.B. 3011, Kano State, Nigeria \\ ${ }^{2}$ Department of Human Anatomy, Faculty of Medicine, Ahmadu Bello University, Zaria, Nigeria \\ ${ }^{3}$ Department of Chemical Pathology, Faculty of Medicine, Ahmadu Bello University, Zaria, Nigeria \\ *Corresponding Author: abdullahiyusufasuku@gmail.com; +2348032878100
}

\begin{abstract}
Visceral adipose tissue is considered the most important anatomic site of adipose tissue aggregation and is considered the hall mark of metabolic syndrome (MetS) phenotype. The aim of the study was to determine sexual dimorphism in visceral adiposity measures, parameters and biomarkers of metabolic syndrome among Hausa ethnic group in Kano, Nigeria. The study was a cross sectional study including 465 participants of Kano, with a mean age of 34.4 years and 32.0 years for males and females respectively. Systematic random sampling technique was employed for subject recruitment. Weight, height, waist circumference (WC) and body mass index BMI were obtained using standard protocol. Overnight fasting blood sample was obtained for high density lipoprotein cholesterol (HDL-c), total cholesterol (TC), triglyceride (TG), low density lipoprotein cholesterol (LDL-C), uric acid and adiponectin estimation using standard laboratory protocols. Visceral adipose tissue was estimated using visceral adiposity index (VAI) and WC. It was observed that VAI, FBG, HDL and TC were significantly higher in females. There was no significant sex difference in WC, TG, and LDL, Serum adiponectin, uric acid, systolic and diastolic blood pressure. In conclusion, the serum uric acid and adiponectin levels did not show sexual dimorphism. Only some of the Mets parameters are sexually dimorphic. While VAI was higher in females, WC did not show sexual dimorphism.
\end{abstract}

Keywords: Biomarkers, metabolic syndrome indices, sexual dimorphism, visceral adiposity

\section{INTRODUCTION}

The metabolic syndrome is a cluster of interrelated common clinical disorders, including hypertension, hyperglycemia, glucose intolerance and dyslipidaemia in addition to obesity (Moller and Kaufman, 2005). It is defined based on the presence of three or more of the following criteria: abdominal obesity with waist circumference $>94 \mathrm{~cm}$ for men or $>80 \mathrm{~cm}$ for women (Grundy et al.,2005), triglycerides $>150 \mathrm{mg} / \mathrm{dl}$, high density lipoprotein cholesterol (HDL-cholesterol) $<40$ $\mathrm{mg} / \mathrm{dl}$ for men or $<50 \mathrm{mg} / \mathrm{dl}$ for women (Bergman et al., 2006), blood pressure $>130 / 85 \mathrm{mmHg}$ (Tremblay et al., 2004) and fasting glucose $>100 \mathrm{mg} / \mathrm{dl}$ (Grundy et al., 2005) It is documented that accumulation of excess body fat, particularly intra-abdominal visceral fat promotes the development of the metabolic syndrome (Kissebah et al., 1982; Fujioka et al., 1987; Grundy et al.,1999; Kahn et al., 2000).

Adiponectin is a novel peptide abundantly expressed in adipose tissue (Matsuzawa, 2005). This adipocytokine is very attractive because of its antiatherogenic (Okamoto et al., 2002; Ouchi et al., 2001), anti-diabetic (Yamauchi et al., 2002; Stefan et al., 2003) and anti-inflammatory (Maeda et al., 2002; Engeli et al., 2003) properties. It's a biomarker of MetS as low plasma levels characterize both obesity and adverse metabolic parameters ( $\mathrm{Hu}$ et al., 1996; Arita et al., 1999; Hotta et al., 2000; Weyer et al.,
2001; Engeli et al., 2003). While hyperuricemia is associated with adverse metabolic states (Billiet et al., 2014), hyper adiponectinemia has been proven to be protective (Kadowaki et al., 2006; Lara-castro et al., 2007; Ghantous et al., 2015).

Ethnicity and race are known to affect visceral adipose reserve (Lear et al., 2007; Misra and Khurana, 2009), serum adiponectin (Weyer et al., 2001; Stefan et al., 2003) and uric acid (Mark et al., 2012). Because of the close association between visceral adipose tissue and these biomarkers with metabolic syndrome components, their ethnic variation may affect measures and sexual differences of the metabolic syndrome indices in a population. Moreover, since the various components of MetS are associated with different but interrelated complications, the extent of sexual difference in each of the components may be a pointer to the susceptibility of each gender to a particular complication of the MetS. There is paucity of data on the sexual difference in visceral measures of adipose tissue, MetS biomarkers and indices especially among the Hausa population. The aim of the study was to determine sexual dimorphism in visceral adiposity measures, parameters and biomarkers of metabolic syndrome among Hausa ethnic group in Kano, Nigeria. 
Bajopas Volume 10 Number 2 December, 2017

\section{MATERIALS AND METHODS \\ Target Group and Sample Size}

Systematic random sampling technique was employed in selecting 465 [266 males (57\%) and 199 females $(43 \%)$ ] original Hausa ethnic group of Kano based on a history of at least two parental generation being Hausas from Kano. Participants were recruited from outpatient units of Murtala Muhammad specialist Hospital, Khadija Memorial Hospital, SU clinic, General Hospital Dawakin - Tofa and the old campus of Bayero University, Kano. The study included only subjects in the age range of 18 years to 68 years. Subjects with pregnancy, abdominal or pelvic space occupying lesions, congenital and / or acquired spinal or digit deformity, were however excluded. Subjects that were on medications that could interfere with any component of metabolic syndrome were also excluded. Ethical approval was obtained from Kano state hospitals management board and written informed consent obtained from the subjects.

\section{Anthropometry and Derived Indices}

Height was measured to the nearest $0.1 \mathrm{~cm}$ as the vertical distance between the standing surface and the vertex of the head while the subject was standing erect in the frank forth plane and without shoes using a stadiometer. The weight was measured in kilograms using a digital weighing scale while the subject is in light clothes. The body mass index was be calculated by dividing the weight in kilograms by the square of the height in meters and the result expressed in $\mathrm{kg} / \mathrm{m}^{2}$. Waist circumference was measured in centimeter with a non- stretchable plastic tape horizontally placed over the unclothed abdomen at the narrowest point between the lowest rib and the iliac crest.

Visceral adiposity was estimated using the sex specific mathematical model (Visceral Adiposity Index) proposed Amato and Giordano, (2010). The index is reported to be highly correlated with visceral adiposity measured by sophisticated methods such as magnetic resonance imaging and computer tomography scan, it is therefore presumed to be a reliable predictor of adipose tissue reserve (Zhang et al., 2013a).

VAI $($ Male $)=\frac{\dot{W C}}{39.68+(1.88 \times \mathrm{BMI})} \times \frac{T G}{1.03} \times \frac{\mathbf{1 . 3 1}}{\mathrm{HDL}}$

$$
\begin{aligned}
V A I(\text { Female })= & \frac{W C}{36.58+(1.89 \times \mathrm{BMI})} \times \frac{\boldsymbol{T G}}{\mathbf{0 . 8 1}} \\
& \times \frac{\mathbf{1 . 3 1}}{\boldsymbol{H D L}}
\end{aligned}
$$

Where WC is waist circumference, TG is serum triglyceride, HDL is serum high density lipoprotein, and BMI is body mass index.

\section{Measurement of Serum Parameters}

For the estimation of serum TC, TG, LDL and HDL - C, FBG, uric acid and adiponectin, blood specimen was collected from 161 subjects after 10 to 12 hours of fasting via superficial veins of the upper limb. From each selected subject, $5 \mathrm{ml}$ of venous blood sample was collected using a sterile $21 \mathrm{G}$ needle fitted with syringe. Blood collection was done during the morning hours to avoid the effect of diurnal variation or circadian rhythm in the blood parameters to be measured. Standard technique of venipuncture and universal safety precaution was employed. Blood sample was transferred into a plain blood specimen bottle and allowed to stand until it was properly clotted. The blood samples were preserved in an ice pack insulating container to preserve the temperature and then transported to the lab immediately after each exercise of sample collection. Sample was then centrifuged at 300rpm for 5 minutes after which serum was separated and immediately used for analysis.

Serum glucose was measured using the enzymatic method of Trinder (1969). Serum TC, TG and HDL concentrations were measured using enzymatic method by Wybenga, et al. (1970). Serum uric acid concentration was measured using Caraway method (1955). Serum adiponectin concentration was determined using the Solid - Phase ELIZA method (Pischon et al., 2003).

\section{Statistical Analyses}

The data were expressed as mean \pm standard deviations, Student's t test was used to compare between males and females. SPSS version 20 (IBM Corporation, NY) software was used for statistical analyses and $P<0.05$ was set as level of significance.

\section{RESULTS}

Table 1 shows the sexual dimorphism in anthropometric parameters. There was statistically significant sex differences in height and weight, with males having higher mean values. No significant sexual dimorphism was observed in age, BMI and waist circumferences.

Table 1: Sexual dimorphism in anthropometric parameters

\begin{tabular}{lllllllll}
\hline \multicolumn{7}{c}{ Male $(\mathbf{n = 2 6 6})$} & \multicolumn{7}{l}{ Female $\mathbf{( n = 1 9 9 )}$} \\
\hline Variables & Mean & SD & Min-max & Mean & SD & Min-max & t & P Value \\
\hline Age & 34.45 & 13.52 & $18-68$ & 32.06 & 15.18 & $18-65$ & 1.79 & 0.075 \\
Height $(\mathrm{cm})$ & 169.15 & 6.27 & $142-182.3$ & 158.53 & 6.83 & $136.9-175$ & 17.39 & $<0.0001$ \\
Weight $(\mathrm{Kg})$ & 63.03 & 12.28 & $40.5-98.3$ & 55.86 & 12.99 & $36-108.9$ & 6.08 & $<0.0001$ \\
BMI & 21.98 & 3.93 & $14.52-34.33$ & 22.19 & 4.7 & $12.96-39.15$ & -0.52 & 0.602 \\
WC $(\mathrm{cm})$ & 77.28 & 11.17 & $57-111$ & 76.02 & 13.00 & $51-118.5$ & 1.12 & 0.261 \\
\hline
\end{tabular}

BMI: body mass index, Standard deviation, WC; waist circumferences

From Table 2 no statistically significant sex difference was observed in the mean values of serum uric acid, adiponectin, LDL - $\mathrm{C}$ and TG. In FBG, TC and HDL a statistically significant higher was observed in the female participants. 
Bajopas Volume 10 Number 2 December, 2017

Table 2: Sex difference in the metabolic syndrome serum biomarkers and indices

\begin{tabular}{|c|c|c|c|c|c|c|c|c|}
\hline \multirow[b]{2}{*}{ Variables } & \multicolumn{3}{|c|}{ Male $(n=120)$} & \multicolumn{3}{|c|}{ Female $(n=41)$} & \multirow[t]{2}{*}{$\mathrm{t}$} & \multirow[b]{2}{*}{$P$ value } \\
\hline & Mean & SD & Min-max & Mean & SD & Min-max & & \\
\hline Uric Acid & 5.51 & 1.95 & $3.1-11.3$ & 6.03 & 2.42 & $2.9-10.10$ & -1.38 & 0.17 \\
\hline Adiponectin & 23.28 & 5.96 & $7.8-33.90$ & 22.55 & 7.45 & $14.4-33.9$ & 0.63 & 0.52 \\
\hline FBG & 84.67 & 24.73 & $53.6-187.2$ & 100.63 & 34.9 & $54.6-176.4$ & -3.19 & 0.0017 \\
\hline TC & 174.35 & 32.31 & $123.7-256.1$ & 187.32 & 43.85 & $127.3-290.7$ & -2.02 & 0.045 \\
\hline $\mathrm{HDL}-\mathrm{C}$ & 44.1 & 6.32 & $28-54.1$ & 47.83 & 6.71 & $38.9-60.6$ & -3.21 & 0.0016 \\
\hline TG & 117.18 & 31.76 & $74.3-196.5$ & 121.83 & 29.25 & $80.4-165$ & -0.83 & 0.41 \\
\hline LDL- C & 106.81 & 32.44 & $58.14-192.82$ & 115.12 & 44.05 & $54.36-214.46$ & -1.29 & 0.2 \\
\hline
\end{tabular}

FBG: fasting blood glucose, TC: total cholesterol, HDL - c: high density lipoprotein cholesterol, TG: triglyceride, LDL - c: low density lipoprotein cholesterol VAI was significantly higher in females.

Figure 1 shows that no statistically sexual dimorphism in systolic and diastolic blood pressure. However, statistically significant higher visceral adiposity index (VAI) was observed in female compared to male counter parts

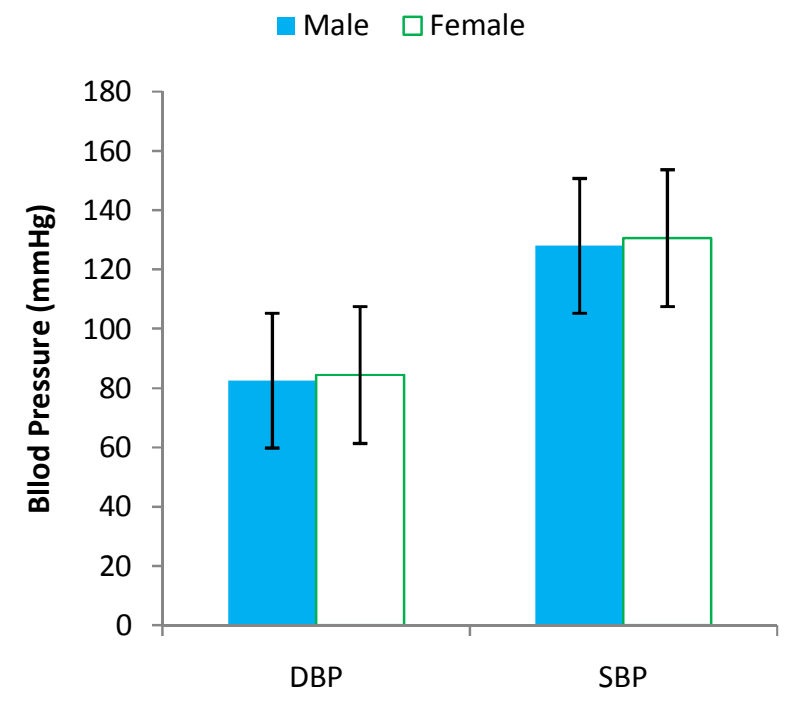

Figure 1: Sexual dimorphism in systolic and diastolic blood pressure

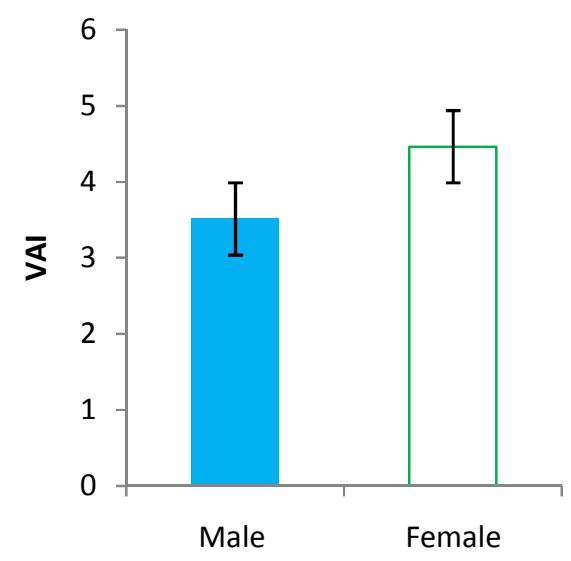

Figure 2: Sexual dimorphism in visceral adiposity index (VAI). $\mathrm{P}<0.05$ 
Bajopas Volume 10 Number 2 December, 2017

\section{DISCUSSION}

The significantly higher mean serum concentration of FBG and TC observed in females of this study may be a pointer to the higher incidence of adverse metabolic profile in the females compared to males. This impression is strengthened by the higher mean value of visceral adiposity in females as measured by VAI which has been shown to be the hall mark of MetS phenotype (Bay, 2011). Similar to this study, many previous studies reported a higher mean value for $\mathrm{HDL}-\mathrm{C}$ in females when compared to males (Sabir et al., 2013).

The observation from this study that VAI is higher in females slightly deviates from previous studies (Kuk et al., 2005; Amato et al., 2010; Amato and Giordano, 2014) which were conducted on other populations that differ from those of this study in terms of race, ethnicity and environmental influence and these variations in the characteristics of the study population may be the basis of this deviation observed. Salomon et al. (2011) showed that differences in methods employed for visceral fat estimation may yield different results. Therefore, since various observers employed different technique, this may account for differences in findings. Also, because the study included women in the reproductive age, the female subjects are likely to have laxed anterior abdominal wall muscles resulting from pregnancies and deliveries and as such likely to have raised $W C$ measurement.

Since WC is a component of the sex specific model employed in this study for estimating visceral fat, this may account for the higher values of VAI observed in females of this study and may probably represent an inherent draw back in this model proposed by Amato and Giordano, (2014). This means that the accuracy of this model may be limited in some subjects exemplified by multiparous women in whom other factors other than intra abdominal visceral fat may contribute to the value of WC measurement. In keeping with this study however, Andreas et al, (2013) used VAI as the tool for visceral adipose tissue estimation and showed the mean value to be higher in females.

In this study, unlike many studies comparing the mean values of uric acid and adiponectin in males and females, serum uric acid and adiponectin showed no statistically significant difference in their mean values. As independent biomarkers of MetS, SUA have been shown to be higher in males (Zhang et al., 2013b), while adiponectin is higher in females (Pedersen et al., 2004; Mattsson and Olsson, 2007). In this study, there was a slight deviation from this trend in that, no significant difference was observed in the mean values of SUA and adiponectin. The lower level of SUA

\section{REFERENCES}

Amato, M.C and Giordano, C. (2014). Visceral adiposity index: an indicator of adipose tissue dysfunction. International Journal of Endocrinology, (http://www.ncbi.nlm.nih.gov/pmc/articles/P MC4009335/http://www.hindawi.com//ije/20 14/730827/): 730827. in females reported in many studies is attributed to the uricosuric effect of estrogen (Nicholls et al., 1973) and the higher level of adiponectin in females is also thought to be associated with levels of circulating estrogen (Pedersen et al., 2004; Mattsson and Olsson, 2007). Since the level of estrogen significantly drops post menopausally (Lovejoy et al., 2008; Keller et al., 2010), body functions driven principally by this sex hormone may demonstrate a trend reversal.

Considering the age group of subjects recruited for this study, women falling within the post menopausal age range were included and this may explain the absence of significant sexual dimorphism observed for SUA and adiponectin in this particular study. Further, since the indicators of adverse metabolic profile especially the VAI was significantly higher in females, it means the serum level of protective biomarker (adiponectin) will likely decrease while that of SUA will increase in females. This may explain the seemingly reversed trend of SUA and adiponectin seen in this study.

\section{CONCLUSION}

The study revealed that visceral adipose tissue measured by VAI, serum TC, FBG and HDL are higher in females. WC, TG, LDL, uric acid, adiponectin and both systolic and diastolic blood pressure did not show sex differences.

\section{RECOMMENDATION}

Similar studies on other ethnic groups in Nigeria should be conducted to find out if the sexual dimorphism in MetS indicators observed in this study can be applied to other Nigerians.

\section{Acknowledgements:}

We thank all those who volunteered to participate and also those that gave technical assistance in this study.

\section{Funding:}

This work is an extract of a Ph.D. dissertation which was sponsored by Bayero University Research Grant Unit and Tertiary Education Trust Fund (TETfund) of Nigeria.

\section{Conflict of Interest:}

The authors declare that there is no conflict of interest.

Authors' contributions: Asuku, A.Y: concepts, design, definition of intellectual content, literature search, data acquisition and analyses, manuscript preparation, editing and review. Danborno, B: design, definition of intellectual content, manuscript preparation, editing and review. Akuyam, A.S: design, definition of intellectual content, manuscript preparation, editing and review. Timbuak, J. A: definition of intellectual content, manuscript preparation, editing and review. Adamu LH: definition of intellectual content, data analyses, manuscript preparation, editing and review.

Amato, M.C., Giordano, C., Galia, M., Criscimanna, A., Vitabile, S., Midiri, M., Galluzzo, A and Alkamesy, Y. (2010). Study Group: Visceral adiposity index: a reliable indicator of visceral fat function associated with cardiometabolic risk. Diabetes Care, 33:920922. 
Bajopas Volume 10 Number 2 December, 2017

Andersen, L. B. (2006). Physical activity and clustered cardiovascular risk in children: a crosssectional study (The European Youth Heart Study). Lancet,368: 299-304

Andreas, M., Claudia, L. and Alexander, T.M. (2013). Body Adiposity Index and other indexes of body composition in SAPHIR study: Association with cardiovascular risk factors. Obesity, 21, 775-771

Arita, Y., Kihara, S., Ouchi, N., Takahashi, M., Maeda, K., Miyagawa, J., Hotta, K., Shimomura, I., Nakamura, T., Miyaoka, K., Kuriyama, H., Nishida, M., Yamashita, S., Okubo, K., Matsubara, K., Muraguchi, M., Ohmoto, Y., Funahashi, T and Matsuzawa, Y. (1999). Paradoxical decrease of an adipose-specific protein, adiponectin, in obesity. Biochemical and Biophysical Research Communications, 257: 79-83.

Bays, H.E. (2011). Adiposopathy: is "sick fat" a cardiovascular disease? Journal of America College of Cardiology, 57:2461-73.

Bergman, R.N., Kim, S.P., Catalano, K.J., Hsu, I.R., Chiu, J.D and Kabir, M. (2006). Why visceral fat is bad: mechanisms of the metabolic syndrome. Obesity Silver SpringSupplies 1:16S-19S

Billiet, L., Doaty, S., Katz, J.D.and Velasquez, M.T. (2014). Review of hyperuricemia as new marker for metabolic syndrome. ISRN Rheumatology, 85:29-54

Caraway, W.T. (1955). Determination of concentration of serum uric acid. American Journal of Clinical Pathology, 25: 840

Engeli, S., Feldpausch, M., Gorzelniak, K., Hartwig, G., Heintze, U., Janke, J., Mohlig, M., Pfeiffer, A.F., Luft, F.C and Sharma, A.M. (2003). Association between adiponectin and mediators of inflammation in obese women. Diabetes, 52: 942-947.

Fujioka, S., Matsuzawa, Y., Tokunaga, K and Tarui, S. (1987). Contribution of intra-abdominal fat accumulation to the impairment of glucose and lipid metabolism in human obesity. Metabolism, 36: $54-59$.

Ghantous, C.M, Azrak, Z., Hanache, S., Abou-Kheir, W. and Zeidan, A. (2015). Differential role of leptin and adiponectin in cardiovascular system. International Journal of Endocrinology, 5:(34)3-20.

Grundy, S.M. (1999). Hypertriglyceridemia, insulin resistance, and the metabolic syndrome. American Journal of Cardiology, 83: 25F29F.

Grundy, S.M., Cleeman, J.I., Daniels, S.R., Donato, K.A., Eckel, R.H and Franklin, B.A (2005). Diagnosis and management of the metabolic syndrome: an American Heart Association/National Heart, Lung, and Blood Institute Scientific Statement. Circulation, 112(17):2735-52

Hotta, K., Funahashi, T and Arita,Y. (2000) Plasma concentrations of a novel, adipose-specific protein, adiponectin, in type 2 diabetic patients. Arteriosclerosis, Thrombosis and Vascular Biology, 20:1595-1599.
Hu, E., Liang, P and Spiegelman, B.M(1996 ).AdipoQ is a novel adipose-specific gene dysregulated in obesity. Journal of Biological Chemistry, 271: 10697-10703.

Kadowaki, T., Yamauchi, T., Kubota, N., Hara, K., Ueki, K. and Tobe, K.(2006) Adiponectin and adiponectin receptors in insulin resistance, diabetes, and the metabolic syndrome. The Journal of Clinical Investigation, 116: 17841792.

Kahn, B.B and Flier, J.S. (2000) Obesity and insulin resistance. Journal of Clinical Investigations, 106: 473 - 481

Keller C, Larkey L, Distefano JK, (2010). Boehm-Smith E, Records K, Robillard A, Veres S, Al-Zadjali M, O'Brian AM. Perimenopausal obesity. J Womens Health 19: 987-996.

Kissebah, A.H., Vydelingum, N., Murray, R., Evans, D.J, Hartz, A.J., Kalkhoff, R.K.(1982) Relation of body fat distribution to metabolic complications of obesity. Journal of Clinical Endocrinology and Metabolism, 54: 254260.

Kuk JL, Lee S, Heymsfield SB, Ross R. (2005). Waist circumference and abdominal adipose tissue distribution: influence of age and sex. $A m ~ J$ Clin Nutr 81: 1330-1334.

Lara-Castro, C., Fu, Y., Chung, B.H.and Garvey, W.T. (2007) Adiponectin and the metabolic syndrome: mechanisms mediating risk for metabolic and cardiovascular disease. Current Opinion in Lipidology, 18: 263-70.

Lear, S.A, Humphries, K.H., Kohli, S., Chockalingam, A., Frohlich, J.J. and Birmingham, C.L (2007). Visceral adipose tissue accumulation differs according to ethnic background: results ofthe Multicultural Community Health Assessment Trial (M-CHAT). American Journal of Clinical Nutrition,86: 353-359.

Lovejoy JC, Champagne CM, de Jonge L, Xie H, Smith SR. (2008). Increased visceral fat anddecreased energy expenditure during the menopausal transition. Int J Obes 32: 949958.

Maeda, N., Shimomura, I., Kishida, K., Nishizawa, H., Matsuda, M., Nagaretani, H., Furuyama, N., Kondo, H., Takahashi, M., Arita, Y., Komuro, R., Ouchi, N., Kihara, S., Tochino, Y., Okutomi, K., Horie, M., Takeda, S., Aoyama, T., Funahashi, $T$ and Matsuzawa,Y.(2002).Diet-induced insulin resistance in mice lacking adiponectin/ACRP30. Nature Medicine, 8: 731-737.

Mark, D.D., Dong, M.S and Mathew, J.G. (2012). Racial/ Ethnic and gender difference in the relationship between uric acid metabolic syndrome in adolescents: An analysis of NHANES 1999-2006. Metabolism, 61(4): 554561

Matsuzawa, Y(2005). Adiponectin: Identification, physiology and clinical relevance in metabolic and vascular disease. Atherosclerosis. Supplements, 6: 7-14. 
Mattsson, C. and Olsson, T. (2007). Estrogens and glucocorticoid hormones in adipose tissue metabolism. Current Medicine and Chemistry, 4(27):2918-24.

Misra, A. and Khurana, L. (2009) The metabolic syndrome in South Asians: epidemiology, determinants, and prevention. Metabolic Syndrome and Related Disorders,7: 497-514

Moller, D.M and Kaufman, K.D (2005). Metabolic syndrome: a clinical and molecular perspective. Annual Review of Medicine, 56: 45-62.

Nicholls, A., Snaith, M. and Scott, J. (1973). Effect of estrogen therapy on plasma and urinary levels of uric acid. Biomedical Journal,1:449451.

Okamoto, Y., Kihara, S., Ouchi, N., Nishida, M., Arita, Y., Kumada, M., Ohashi, K., Sakai, N., Shimomura, I., Kobayashi, H., Terasaka, N., Inaba, T., Funahashi, $\mathrm{T}$ and Matsuzawa, $Y(2002)$. Adiponectin reduces atherosclerosis in apolipoprotein E-deficient mice. Circulation, 106: 2767-2770.

Ouchi, N., Kihara, S., Arita, Y., Nishida, M., Matsuyama, A., Okamoto, Y., Ishigami, M., Kuriyama, H., Kishida, K., Nishizawa, H., Hotta, K., Muraguchi, M., Ohmoto, Y., Yamashita, S., Funahashi, T and Matsuzawa, Y (2001). Adipocyte-derived plasma protein, adiponectin, suppresses lipid accumulation and class $A$ scavenger receptor expression in human monocyte-derived macrophages. Circulation, 103: 1057-1063.

Pedersen, S. B., Kristensen, K., Hermann, P. A.(2004). Estrogen controls lipolysis by upregulatingalpha2A-adrenergic receptors directly in human adipose tissue through theestrogem receptor alpha. Implications for female fat distribution. Journal of Clinical Endocrinology and Metabolism, 89: 1869-78.

Pischon, T., Hotamisligil, G.S. and Rimm, E.B. (2003). Adiponectin Stability in plasma over 36 hours and within person variation over 1 year. Clinical Chemistry, 49:650-652

Sabir, A.A., S.A. Isezuo, A.E. Ohwovoriole., O.A. Fasanmade, S.A. Abubakar, S. Iwuala, M.T. Umar, (2013). Rural-Urban Difference In Plasma Lipid Levels And Prevalence Of Dyslipidemia In Hausa-Fulani Of NorthWestern Nigeria. Ethnicity \& Disease. 23[3]:374-378)
Salomon EG, Hizon CE, Raboca JC. (2011). Minimum Waist Circumference and Visceral Fat Values by Ultrasonography to Identify Adult Urban Filipinos at Risk for Metabolic Syndrome. Philippine Journal of Internal Medicine, 49(1): 15-21.

Stefan, N., Stumvoll, M., Vozarova, B., Weyer, C., Funahashi, T., Matsuzawa, Y., Bogardus, C and Tataranni, P.A (2003). Plasma adiponectin and endogenous glucose production in humans. Diabetes Care, 26: $3315-3319$

Tremblay, A.J., Despre's, J.P., Piche,' M.E, Nadeau, A., Bergeron, J and Alme'ras, N (2004). Associations between the fatty acid content of triglyceride, visceral adipose tissue accumulation, and components of the insulin resistance syndrome. Metabolism, 53(3):3107 , metabol.2003.10.011.

Trinder, P. (1969). Determination of serum glucose. Annals of clinical biochemistry, 6:24-27

Weyer, C., Funahashi, T andTanaka, S (2001): Hypoadiponectinemia in obesity and type 2 diabetes: Close association with insulin resistance and hyperinsulinemia. Journal of Clinical Endocrinology and Metabolism, 86:1930-1935.

Wybenga, D.R., Pileggi, V.J., Dirstine P.H. and Di Giorgio, j.(1970). Methods of measuring serum lipids. Clinical Chemistry, 16:980

Yamauchi, T., Kamon, J., Minokoshi, Y., Ito. Y., Waki, H., Uchida, S., Yamashita, S., Noda, M., Kita, S., Ueki ,K., Eto, K., Akanuma, Y., Froguel, P., Foufelle, F., Ferre, P., Carling, D., Kimura, S., Nagai, R., Kahn, B.B and Kadowaki, T.(2002). Adiponectin stimulates glucose utilization and fattyacid oxidation by activating AMP-activated protein kinase. Nature Medicine, 8: 1288-1295.

Zhang, Z. Q., Deng, J., He, L. P., Ling, W. H., Su Y. X. (2013a). Comparison of Various Anthropometric and Body Fat Indices in Identifying Cardiometabolic Disturbances in Chinese Men and Women. PLOS ONE 8(8): e70893. doi:10.1371/journal.pone.0070893

Zhang, Z.Q., Liu, Y.H., Xu, Y., Dai, X.W., Ling, W.H. and Su, Y.X. (2013b). The validity of the Body Adiposity Index in predicting percentage body fat and cardiovascular risk factors among Chinese. Clinical Endocrinology, 81:(3) $356-362$ 